\title{
Reproduction of Variability of the Black Sea Level and Pycnocline Characteristics Based on the Adaptive Statistics Method
}

\author{
P. N. Lishaev*, V. V. Knysh, G. K. Korotaev \\ Marine Hydrophysical Institute, Russian Academy of Sciences, Sevastopol, Russian Federation \\ *e-mail: pavellish@mail.ru
}

\begin{abstract}
Retrospective analysis of the Black Sea hydrophysical fields (1993-2014) is carried out including assimilation of the three-dimensional fields of the temperature and salinity pseudo measurements reconstructed before in the model on the horizons within the layer $63-500 \mathrm{~m}$ by the adaptive statistics method. To compare root-mean-square deviations of the temperature and salinity fields from the observations, the reanalysis data (1993-2012) comprising assimilation of the temperature and salinity unperturbed profiles in the model are used. Variability of temperature and salinity (density) profiles in the main pycnocline is reproduced more accurately in the reanalysis for 1993-2014. Root-meansquare deviations of the sea level fields (resulted from the reanalysis for 1993-2014) from the altimetry ones in the first decade of seasonal and inter-annual variability are smaller than those (estimated in the same way) obtained from the reanalysis data for 1992-2015 in which the AVISO data and the sea surface temperature are assimilated. The root-mean-square deviations of the sea level increase in the second decade of the period. It is explained by the fact that decrease of the training set is accompanied by lowering of accuracy in reconstructing the fields of the temperature and salinity pseudo-measurements based on the altimetry and Argo buoys' data. Synoptic variability of the sea currents' fields in 1993-2014 is studied by analyzing the maps of the sea level integral dispersion. The values of sea level dispersion are found to be high on vast areas in the western and eastern parts of the basin. It is conditioned by generation and movement of the Sevastopol anticyclone, formation of synoptic vortices in the southwestern region of the western cyclonic water cycle, dynamics and evolution of the Caucasian anticyclonic vortices and the Batumi anticyclone. The local area to the northwest off Sinop is also noted.
\end{abstract}

Keywords: reanalysis, pseudo measurements, adaptive statistics, RMS deviation, synoptic variability, integral dispersion.

Acknowledgments: the investigation results represented in the section "Development of the method of joint assimilation of the Black Sea altimetry level and the limited measurement data of the Argo profiling floats" are obtained within the framework of the state task on the theme No. 0827-20140011 "Studies of regularities of the marine environment state changes based on the operational observations and the nowcast, forecast and reanalysis system data on the marine environment state" (code "Operational oceanography"). The rest of the investigation results sited in the paper are obtained at the RFBR financial support, grant No. 16-05-00621. The authors express their deep gratitude to V. L. Dorofeev for providing the data on the Black Sea level reconstructed based on reanalysis of the hydrophtsical fields for $1992-2015$.

For citation: Lishaev, P. N., Knysh, V. V. and Korotaev, G. K., 2018. Reproduction of variability of the Black Sea level and pycnocline characteristics based on the adaptive statistics method. Physical Oceanography, [e-journal] 25(4), pp. 251-261. doi:10.22449/1573-160X-2018-4-251-261

DOI: $10.22449 / 1573-160 X-2018-4-251-261$

(C) 2018, P. N. Lishaev, V. V. Knysh, G. K. Korotaev

(C) 2018, Physical Oceanography

Introduction

In previous studies of the authors [1-4] on the basis of assumption on the adiabacity of isothermal and isohaline surface displacements within the main pycnocline of the sea, the method for reconstruction of temperature and seawater 
salinity pseudo-observations in the Black Sea basin by the data of altimetry measurements was proposed. In $[4,5]$ the reanalysis of the Black Sea fields with the consequent improvement in the method of assimilation of the constructed 3D-arrays of temperature and salinity fields was carried out. The method of adaptive statistics, which allows to consider the changes in the dispersion of forecast errors in time and space, is more advanced among the approaches presented in $[4,5]$. Unlike the methods for assimilation of the ocean (sea) hydrophysical parameter measurements in the model based on Kalman ensemble filters [6-8] and variational assimilation of observational data [9-11], the adaptive statistics method does not require the application of powerful computing systems.

In the case of the sea field reanalysis over 2012 with the assimilation of temperature and salinity pseudo-observations in 100-500 m layer in the model by the adaptive statistics method, the results of the refinement of reconstructed hydropohysical parameters are demonstrated [5]. At the same time, it was shown that due to the inaccuracy of the sea upper layer $(2.5-100 \mathrm{~m})$ thermodynamics model root-mean-square deviations (RMS) of the temperature fields, reconstructed in the model from the observations at the horizons of this layer, turned out to be high and mean temperature in cold intermediate layer (CIL) seasonal variation is overestimated.

The purpose of this work is to refine the reconstruction of the sea hydrophysical fields by assimilating the temperature and salinity pseudo-measurements in the model at additional 63-88 m horizons in the reanalysis for 2012. The analysis of seasonal, interannual and decennial variability of the sea level rootmean-square deviations, as well as the one of synoptic variability of current fields by studying the maps of sea level integral dispersion over 1993-2014, was carried out in this work.

\section{Development of joint assimilation method of the Black Sea altimetry level and limited measurement data of Argo profiling floats}

3D fields of temperature and salinity pseudo-measurements over 1993-2002 were reconstructed earlier on the horizons of Marine Hydrophysical Institute (MHI) model in 100-500 m sea level in its deep part (bounded by $500 \mathrm{~m}$ isobath) on the basis of joint analysis of altimetry data and shipboard measurements using the methodology described in [3]. In [4] the proposed method was adapted to the measurements of salinity and temperature profiles by Argo floats. This provided the reconstruction of 3D fields of temperature and salinity pseudo-measurements over 1993-2014 period. Variation of topography of isopycnic, isothermal and isohaline surfaces (as was shown by the analysis performed in [3]) take place mainly in adiabatic way at the depths from 50-100 m to 1100-1200 m. In the light of this result, when carrying out the reanalysis of hydrophysical fields for 2012, the correction of temperature and salinity model values was performed at 63, 75, $88 \mathrm{~m}$ horizons and at all subsequent ones by the adaptive statistics method, whereas previously pseudo-measurements were assimilated only from $100 \mathrm{~m}$ depth.

It turned out that the impact of temperature and salinity pseudo-measurement fields assimilated at 63, 75, $88 \mathrm{~m}$ horizons positively affects the intensity estimation of synoptic eddies. It is also noticeable when reproducing the CIL of the sea. The comparison of Fig. 1 and 2 reveals the fact that the correction of model 
temperature by the pseudo-measurements at $63,75,88 \mathrm{~m}$ horizons results in the increase of CIL renewal degree in winter of 2012 due to which its cold content grows. It can be seen in Fig. 1 by the position of $7.5^{\circ} \mathrm{C}$ isoline. It is also obvious that the CIL thickness determined by the position of upper and lower boundaries of $8^{\circ} \mathrm{C}$ isoline is significantly higher during the entire year than in Fig. 2. The obtained result is also proved by the data of Table 7.1 from [12], in which 2012 year is characterized by high degree of CIL renewal for the entire sea according to hydrologic data.

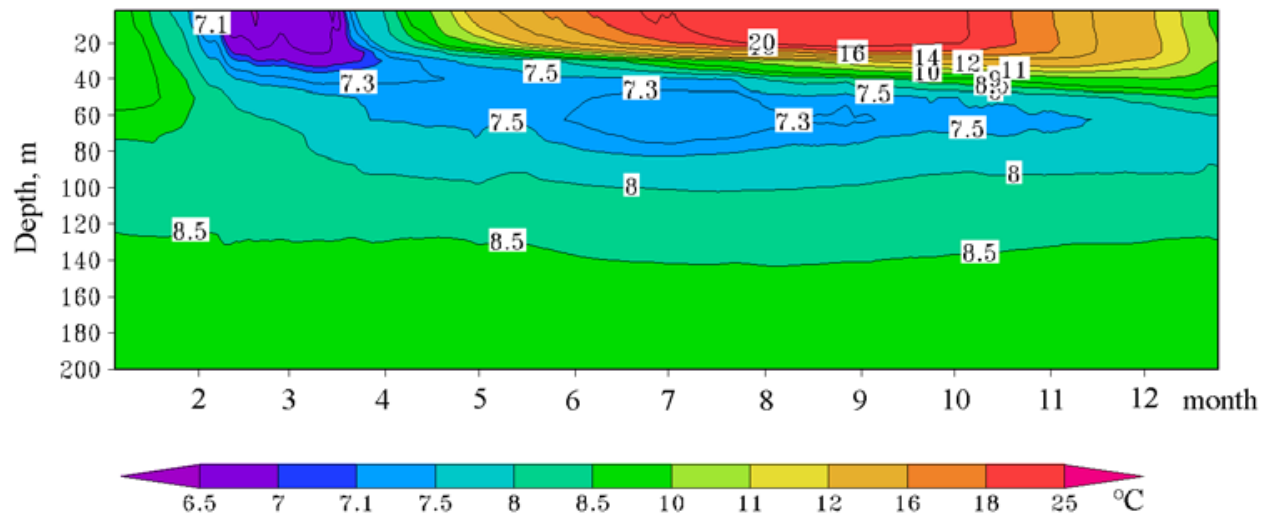

Fig. 1. Diagram of seasonal variability of the average over horizons temperature $\left({ }^{\circ} \mathrm{C}\right)$ reconstructed based on the reanalysis for 2012 including assimilation of pseudo-measurements in 63-500 m layer

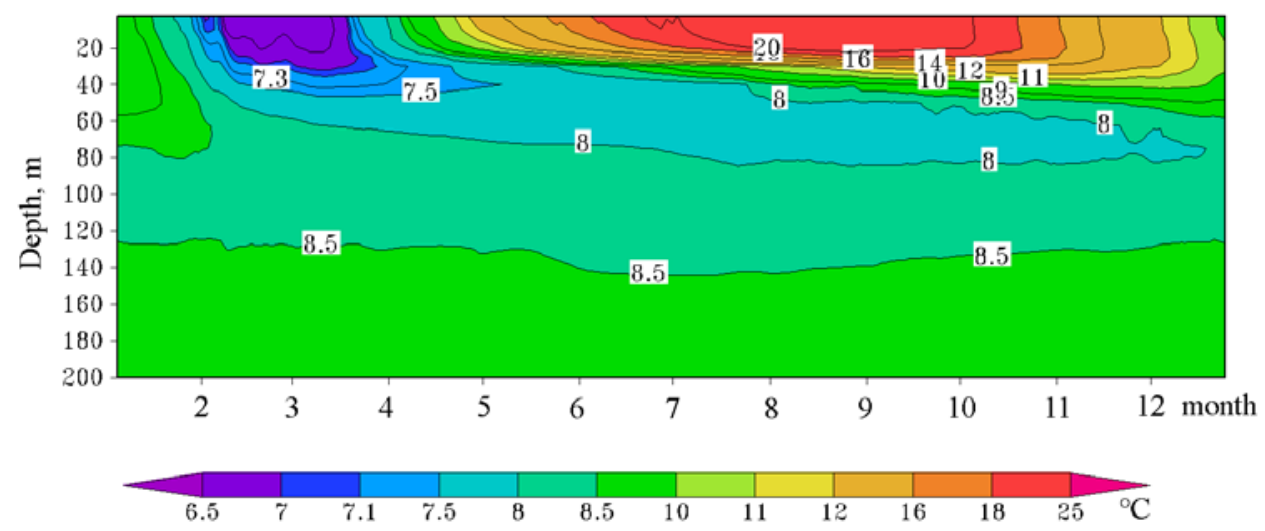

Fig. 2. Diagram of seasonal variability of the average over horizons temperature $\left({ }^{\circ} \mathrm{C}\right)$ reconstructed based on the reanalysis for 2012 including assimilation of pseudo-measurements in the layer 100-500 m

\section{Description of the main calculation}

In the present work the reanalysis of the Black Sea hydrophysical fields over 1993-2014 by the assimilation of 3D-fields of temperature and salinity pseudomeasurements in MHI eddy-resolving model [13] in 63-500 m layer was performed using the adaptive statistics method. Horizontal grid domain step was $5 \mathrm{~km}$. We point out that in the applied MHI model the coefficients of turbulent 
exchange of momentum, heat and salt in vertical direction were calculated using Pacanowsci - Philander parameterization [14].

As the initial fields in the model for 01.01.1993 the ones of temperature, salinity, level and velocities of currents obtained in the reanalysis of the sea hydrophysical fields for 1980-1993 were taken [15]. The values of forecast dispersion errors in the initial moment of time were equal to the ones of typical dispersions [5]. The data of temperature and salinity pseudo-measurements in heat and salt transfer equations were assimilated at each time step. Dispersion of pseudo-measurement errors at the horizons of 63-500 m layer was taken equal to the square of their RMS relative to the available measurements. When carrying out the calculation, the precipitation, evaporations and heat fluxes on the sea surface were taken from the data of ERA-Interim atmospheric reanalysis [16]. Their spatial resolution was $0.75^{\circ}$, temporal one $-12 \mathrm{~h}$. The fields of tangential wind stress friction were known for every $6 \mathrm{~h}$.

Dispersions of pseudo-observation errors, as well as boundary fields, were interpolated at each time step of numerical model. The data of reanalysis over 1993-2014 include daily mean values of temperature, salinity, horizontal and vertical components of current velocity vector, sea level as well as model dispersions of temperature and salinity forecast errors.

Statistic characteristics of errors of temperature and salinity fields reconstructed in the reanalysis. Estimates of root-mean-square deviations between temperature and salinity fields of reanalysis and measurements carried out at hydrologic stations and by Argo floats in the Black Sea were calculated over the entire time period from 1993 to 2014 in 5 layers of deep basin from the surface down to the bottom. It should be noted that the results of the sea field reanalysis over 1993-2012, performed by the assimilation of unperturbed temperature and salinity profiles in the MHI model constructed in [4] according to the method given in [1, 3], were presented earlier in [2]. In [2], the same atmospheric forcing as in the reanalysis with the assimilation of temperature and salinity pseudomeasurements in the MHI model by the method of adaptive statistics [5] was applied. According to the obtained data, the corresponding RMS and mean deviations (M) of temperature and salinity are estimated in order to compare the previous results with this calculation. Mean deviations were calculated by subtracting the temperature and salinity of the values measured at hydrologic stations and by Argo floats from the model values. RMS and MD values for the temperature are given in Table 1, for salinity - in Table. 2.

According to Table 1 , it is impossible to give preference to any reanalysis data in $0-5$ and 5-30 m layers. In all calculations the maximum RMS values are obtained in 5-30 m layers, which is explained by the drawbacks of the sea upper layer thermodynamics model. In the sea active layer, that includes the main pycnocline (30-100 and 100-300 m layers), temperature RMS according to the data of the present calculation with assimilation of temperature and salinity pseudo-measurements by adaptive statistics method is lower than in the reanalysis with the assimilation of temperature and salinity unperturbed profiles. The same relation between RMS is observed in 500-2000 m layer. In 300-500 m layer RMS values differ from each other slightly. 
Root-mean-square (RMS) and mean (M) deviations of the model-derived temperature fields: I - based on the adaptive statistics method; II - using assimilation of the temperature and salinity unperturbed profiles

\begin{tabular}{c|c|c|c}
\hline \multirow{2}{*}{ Layer, $\mathrm{m}$} & \multicolumn{2}{|c|}{ RMS } & M \\
\cline { 2 - 4 } & $\mathrm{I}$ & $\mathrm{II}$ & $\mathrm{I}$ \\
\hline $0-5$ & 1.559 & 1.963 & -0.830 \\
$5-30$ & 3.331 & 3.155 & 1.220 \\
$30-100$ & 0.953 & 1.239 & 0.320 \\
$100-300$ & 0.130 & 0.248 & -0.003 \\
$300-500$ & 0.036 & 0.037 & 0.0001 \\
$500-2000$ & 0.012 & 0.019 & 0.109 \\
\hline
\end{tabular}

Table 2

Root-mean-square (RMS) and mean (M) deviations of the model-derived salinity fields: I - based on the adaptive statistics method; II - using assimilation of the temperature and salinity unperturbed profiles

\begin{tabular}{c|c|c|c}
\hline \multirow{2}{*}{ Layer, $\mathrm{m}$} & \multicolumn{2}{|c|}{ RMS } & M \\
\cline { 2 - 4 } & $\mathrm{I}$ & $\mathrm{II}$ & $\mathrm{I}$ \\
\hline $0-5$ & 0.625 & 0.624 & 0.034 \\
$5-30$ & 0.487 & 0.485 & -0.098 \\
$30-100$ & 0.413 & 0.500 & -0.134 \\
$100-300$ & 0.176 & 0.343 & -0.007 \\
$300-500$ & 0.043 & 0.051 & -0.010 \\
$500-2000$ & 0.025 & 0.019 & 0.004 \\
\hline
\end{tabular}

As follows from Table 1, the temperature reconstructed in the present calculation is underestimated in 0-5 m surface layer and 100-300 m one. The maximum temperature overestimation was obtained in the upper 5-30 m layer in which the assimilation of pseudo-measurements was not performed. In 30-100 m layer temperature $\mathrm{MD}$ is significantly lower which is explained by the model temperature correction by pseudo-measurements at 63, 75, 88, 100 m horizons. In 500-2000 m deep layer insignificant temperature overestimation is due to weak spatial variability of the sea thermohaline parameters.

The comparison of RMS of salinity reconstructed in two reanalyses (Table 2) indicates that in $0-5$ and 5-30 m layers these statistic characteristics are almost the same. The calculated salinity RMS estimation in the main halocline (30-100 and 100-300 m layers) and deeper (300-500 m layer) is significantly lower according to the data of reanalysis with salinity pseudo-measurement assimilation in the model by adaptive statistics method. This result is explained by a good quality of 3D salinity pseudo-measurement fields reconstructed in the pycnocline. In all the layers, except for $0-5$ and 500-2000 m ones, mean deviations of salinity are negative which indicates its underestimation in these layers. It should be noted that salinity MD values in all sea layers are small. 
Statistic characteristics of accuracy of sea level fields reproduced in the reanalysis. The results of sea field reanalysis over 1992-2015 published in [17, 18] allow one to carry out the comparison of two calculation methods. Reanalysis of $[17,18]$ was carried out using the assimilation of level reconstructed by the altimetry, sea surface temperature satellite measurements and combined temperature and salinity profiles in the MHI model. The latter were annual average (according to the data of available measurements) temperature and salinity profiles corrected by climatic seasonal variability. In $[17,18]$ the same atmospheric fields as in our calculations were used.

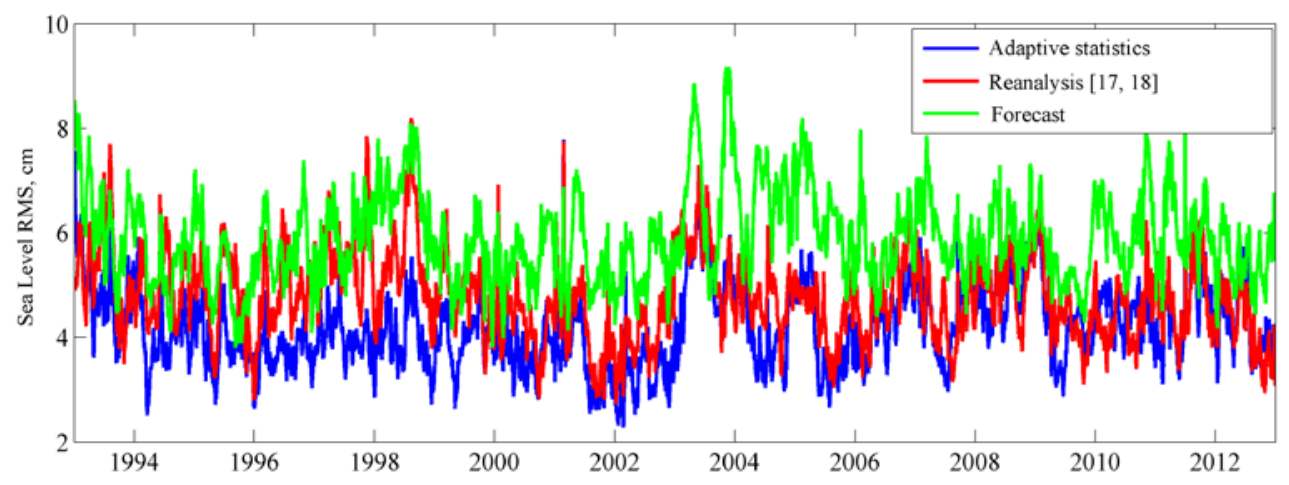

Fig. 3. Seasonal and inter-annual variability of root-mean-square deviations of the reconstructed sea level (relative to the altimetry one)

Altimetric sea level fields calculated for each day over 1993-2014 provided the estimation of model sea level RMS according to the data of two reanalyses. It is of interest to compare them with the sea level RMS obtained by the data of purely prognostic calculation. The latter was carried out for 20 years from 1993 to 2012 with the use of ERA-Interim reanalysis atmospheric fields [16]. It can be seen in Fig. 3 that the level RMS in the prognostic calculation is significantly higher. The sea level RMS values (regarding the altimetric one) according to the data of our reanalysis in the first decade of the considered period are higher than according to the data of reanalysis from $[17,18]$. This is due to the fact that in the first decade of 1993-2014 period the covering with temperature and salinity measurements at hydrologic stations in the deep part of the sea was significantly higher [3] than in the second decade. According to this, the accuracy of temperature and salinity pseudo-measurement reproduction also turned out to be higher in this area. The second decade is characterized by limited data of thermohaline parameter measurements at certain hydrologic stations and Argo profiling floats. In Fig. 3 it is obvious that in this decade the sea level RMS values in our reanalysis slightly increased. Their extreme values are comparable with the sea level RMS from the reanalysis given in $[17,18]$. The differences between the values of level field RMS in the considered reanalyses can be also due to the fact that different methods for the sea altimetry level assimilation in the model are used. The location of the main structures in the sea level (western and eastern cyclonic gyres, cyclonic and anticyclonic eddies) in our reanalysis and in altimetry level, reconstructed for each day by AVISO data on level anomalies [19], is close as temperature and salinity 
pseudo-measurements are tied to altimetry level [3, 4]. The location of the mentioned level structures in the reanalysis of the sea fields carried out in $[17,18]$ can be somewhat different from the location of structures in the altimetry level. We point out that in contrast to our method in [17] more accurate assimilation algorithm based on the use of trackwise values of altimetry sea level anomalies was applied. In our case we use AVISO maps during the assimilation. When creating these maps the interpolation of altimetry observations was performed, and this introduces additional errors.

An important conclusion from the analysis of the results of seasonal, interannual and decadal sea level RMS variability comparison in two reanalyses is that epy course of both RMS curves is basically the same. Extreme sea level RMS values in the reanalysis over 1993-2014 (which was carried out with the assimilation of 3D fields of temperature and salinity pseudo-measurements by the adaptive statistics method) in the second decade of the period are somewhat higher than in the first one.

\section{Long-term synoptic variability of the basin}

A large chapter in [20] is devoted to the study of synoptic vortex formation variability in the Black Sea from the data of long-term hydrological array and synchronous hydrological surveys. Particularly, spatial distribution of temperature and salinity root-mean-square deviations in different sea levels was analyzed in it as synoptic variability characteristic. In the same way the understanding of synoptic variability of the Black Sea fields of currents, temperature and salinity over 1993-2014 can be obtained investigating the most important two-dimensional hydrodynamic function - the sea level. This is due to the fact that level derivatives characterize geostrophic surface currents in the sea. Moreover, in the first approximation the sea level is calculated as an integral taken from the surface to the bottom from the anomaly of sea water density (temperature and salinity).

We shall refer to the analysis of sea level integral dispersion calculated by the data of our reanalysis in the following way. Mean sea level in each point of the grid domain was calculated as a sum of daily average level values over 1993-2014 divided by the number of the days. Then, the integral dispersion of level fluctuations was calculated in the same points in an ordinary way. The maps of sea level integral dispersion (Fig. 4) provide an understanding of the character of synoptic structure distribution.

According to Fig. 4, a, the increased synoptic variability of level field and, consequently, the one of the fields of currents, temperature and salinity in 19932014 is observed in two rather wide areas of the Black Sea deep part - in the western and eastern as well as in the local zone northward of Sinop. In the western area synoptic variability is due to the dynamics of Sevastopol anticyclonic gyre and also two local subregions of increased values of sea level integral dispersion are observed in it. The first subregion is located in Seavastopol anticyclone generation zone (dispersion value is more than $20 \mathrm{~cm}^{2}$ ), the second one - in the southwestern zone of western cyclonic gyre of waters (dispersion value is more than $15 \mathrm{~cm}^{2}$ ). Quite often a dipole structure of cyclone-anticyclone vortices is formed in this zone, which was discovered due to the use of the adaptive statistics method in our reanalysis [5]. In PHYSICAL OCEANOGRAPHY VOL. 25 ISS. 4 (2018) 
the local deep zone northward of Sinop the maximum dispersion value is about $15 \mathrm{~cm}^{2}$.
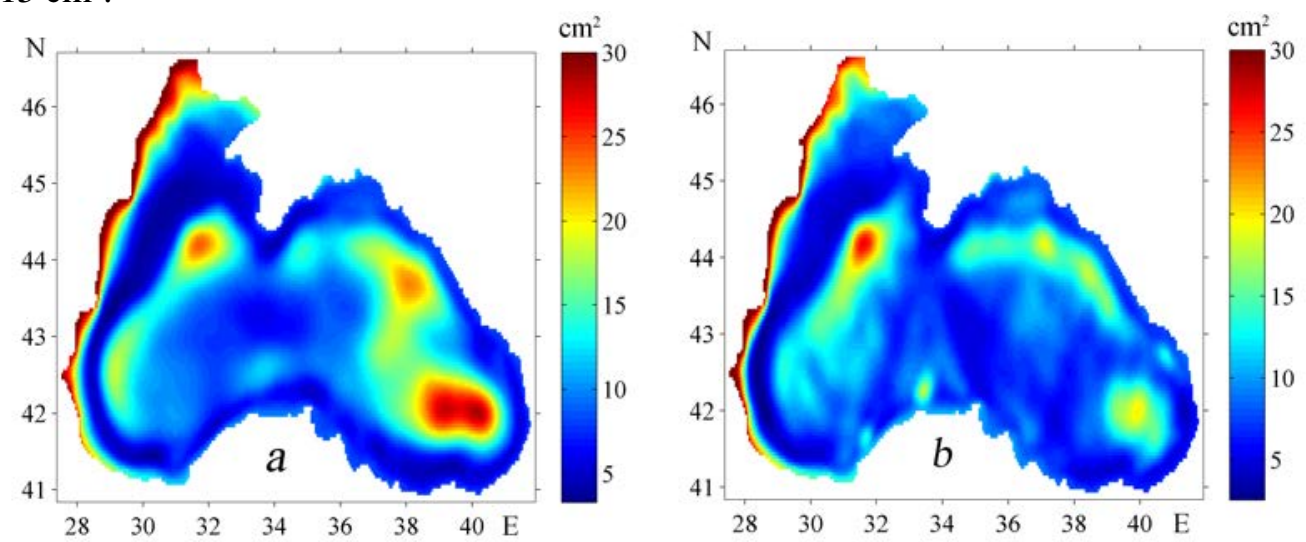

Fig. 4. Dispersion $\left(\mathrm{cm}^{2}\right)$ of the sea level: $a$ - based on the data of the reanalysis performed by the adaptive statistics method; $b$ - based on the reanalyses in $[17,18]$

In the eastern wider area the synoptic variability is caused by the movement and evolution of the Caucasian anticyclonic eddies (the dispersion value is $20 \mathrm{~cm}^{2}$ ) and, to a greater extent, by the dynamics and evolution of the Batumi anticyclone (25 $\mathrm{cm}^{2}$ dispersion value). An increase in the integral sea level dispersion along the northern, northwestern, western and southwestern coasts and offing is noticeable (Fig. 4, a), which is apparently due to wave processes in the sea. We note the paper [21], which presents the results of a regional operational forecast of water circulation in the eastern part of the Black Sea according to a model with $1 \mathrm{~km}$ spatial resolution. The features of synoptic variability obtained in our calculation in the sea southeastern region are confirmed by the data from [21].

Relatively small values of the integral dispersion $\left(5 \mathrm{~cm}^{2}\right)$ are visible along the northwestern, western and southwestern sea continental slopes, as well as near the southern coast of Crimea and in the area of Kizilirmak and Sinop anticyclones. Rather weak synoptic variability is manifested along the Anatolian coast. Integral dispersion distribution shown in Fig. 4, a can be compared with the analogous dispersion map from [22] created according to the data altimetry observations. The increased sea level RMS values which are due to Sevastopol anticyclonic gyre dynamics are observed, just like in our calculation, in the western part of the basin and along the Rim Current (RC). Similar areas of increased synoptic variability of currents, temperature and salinity fields are also obtained by the data of reanalysis over 1992-2015 from [17, 18] (Fig. 4, b). Remarkable examples of the Black Sea level fields in different dates of 2006 demonstrating the BSRC meandering, formation of synoptic and mesoscale eddies on the right from it and determining the abovementioned dispersion level distribution, are given in [23] according to the results of calculation by MHI model with $1.64 \mathrm{~km}$ spatial distribution.

\section{Conclusion}

The study of temperature, salinity and the Black Sea level fields was carried out by the data of their evolution in retrospective analysis of hydrophysical fields over 1993-2014 carried out applying the assimilation of 3D fields of temperature and 
salinity pseudo-measurements in the MHI model in 63-500 m layer by adaptive statistics method. Temperature and salinity fields from the data of reanalysis over 1993-2012 from [2], as well as the sea level fields from the data of reanalysis over 1992-2015 from $[17,18]$ and according to the data of purely prognostic calculation over 1993-2012 were involved in order to perform the comparison.

The performed study shows that using the assimilation of temperature and salinity pseudo-measurements in the model by the adaptive statistics method, it is possible to reproduce the realistic variability of thermochaline characteristics in the main pycnocline. It was determined that the sea level RMS values according to our calculation in the first decade of the considering period (when more observations of the temperature and salinity profiles than in the second decade were available) are smaller than in the reanalysis data from $[17,18]$. This indicates the increase in reproduction accuracy of temperature and salinity 3D-fields according to altimetry data as the training sample grows. The features of the seasonal, interannual and decadal variability of sea level RMS obtained from reanalysis data with the assimilation of pseudo-measurements by the adaptive statistics method and according to reanalysis data from $[17,18]$ are almost identical. Extreme values of sea level RMS in the reanalysis over 1993-2014 are somewhat higher in the second decade of the period which is due to lower covering with temperature and salinity measurements from Argo floats.

The study of spatial structure of sea level field integral dispersion calculated by the data of the reanalysis over 1993-2014 and the one over 1992-2015 from $[17,18]$ allows one to assess the synoptic variability character of currents, temperature and salinity fields in the Black Sea. Synoptic variability intensity of these fields in our reanalysis is somewhat lower than in the reanalysis from $[17,18]$ as in these works altimetry level and sea surface temperature were assimilated to correct of the upper 50-m layer dynamics and thermodynamics. Sea level integral dispersion obtained from the data of our reanalysis is qualitatively close to the one calculated by the data of reanalysis from $[17,18]$ and by the data of altimetry observations from [22].

Original method for assimilation of temperature and salinity 3D pseudomeasurement fields in eddy-resolving circulation model on the basis of adaptive statistics algorithm supplemented by assimilation of surface temperature and altimetry sea level in the upper layer will provide a reconstruction of the Black Sea hydrologic fields with the best accuracy.

\section{REFERENCES}

1. Korotaev, G.K., Lishaev, P.N. and Knysh, V.V., 2015. Technique of the Black Sea Temperature and Salinity Measurement Data Analysis Using Dynamic Altimetry Level. Physical Oceanography, [e-journal], (2), pp. 24-38. doi:10.22449/1573-160X-2015-2-24-38

2. Korotaev, G.K., Sarkisyan, A.S., Knysh, V.V. and Lyshaiev, P.N., 2016. Reanalysis of Seasonal and Interannual Variability of Black Sea Fields for 1993-2012. Izvestiya, Atmospheric and Ocean Physics, [e-journal] 52(4). pp. 418-430. https://doi.org/10.1134/S0001433816040071

3. Korotaev, G.K., Lishaev, P.N. and Knysh, V.V., 2016. Reconstruction of the Three-Dimensional Salinity and Temperature Fields of the Black Sea on the Basis of Satellite Altimetry Measurements. Izvestiya, Atmospheric and Oceanic Physics, [e-journal] 52(9), pp. 961-973. https://doi.org/10.1134/S0001433816090152 
4. Knysh, V.V. and Lishaev, P.N., 2016. Improvement of the Method for Reconstructing the Temperature and Salinity Three-Dimensional Fields of the Black Sea Based on Insufficient Measurements and Altimetry. Physical Oceanography, [e-journal] (6), pp. 3-14. doi:10.22449/1573-160X-2016-6-3-14

5. Korotaev, G.K., Knysh, V.V., Lishaev, P.N. and Demyshev, S.G., 2018. Application of the Adaptive Statistics Method for Reanalysis of the Black Sea Fields Including Assimilation of the Temperature and Salinity Pseudo-Measurements in the Model. Physical Oceanography, [e-journal] 25(1), pp. 36-51. doi:10.22449/1573-160X-2018-1-36-51

6. Evensen, G., 2003. The Ensemble Kalman Filter: Theoretical Formulation and Practical Implementation. Ocean Dynamics, [e-journal] 53(4), pp. 343-367. doi:10.1007/s10236-003-0036-9

7. Belyaev, K.P., Tanajura, C.A.S. and Tuchkova, N.P., 2012. Comparison of Methods for ARGO Drifters the Data Assimilation into a Hydrodynamic Model of the Ocean. Oceanology, [e-journal] 52(5), pp. 593-603. doi:10.1134/S0001437012050025

8. Kaurkin, M.N., Ibrayev, R.A. and Belyaev, K.P., 2016. Data Assimilation into the Ocean Dynamics Model with High Spatial Resolution Using Ensemble Optimal Interpolation (EnOI). Oceanology, [e-journal] 56(6), pp. 774-781. doi:10.1134/S0001437016060059

9. Gejadze, I.Yu., Le Dimet, F.-X. and Shutyaev, V., 2008. On Analysis Error Codispersions in Variational Data Assimilation. SIAM Journal on Scientific Computing, [e-journal] 30(4), pp. 1847-1874. https://doi.org/10.1137/07068744X

10. Zalesny, V.B., Gusev, A.V. and Moshonkina, S.N., 2013. Numerical Model of the Hydrodynamics of the Black Sea and the Sea of Azov with Variational Initialization of Temperature and Salinity. Izvestiya, Atmospheric and Oceanic Physics, [e-journal] 49(6), pp. 642-658. https://doi.org/10.1134/S0001433813060133

11. Agoshkov, V.I., Parmuzin, E.I. and Shutyaev, V.P., 2013. Observational Data Assimilation in the Problem of Black Sea Circulation and Sensitivity Analysis of Its Solution. Izvestiya, Atmospheric and Oceanic Physics, [e-journal] 49(6), pp. 592-602. https://doi.org/10.1134/S0001433813060029

12. Ilyin, Yu.P., Repetin, L.N., Belokopytov, V.N., Goryachkin, Yu.N., Dyakov, N.N., Kubryakov, A.A. and Stanichnyi, S.V., 2012. Gidrometeorologicheskiye Usloviya Morey Ukrainy. Tom 2. Chernoye More [Hydrometeorological Conditions of the Seas of Ukraine. Vol. 2. Black Sea]. Sevastopol, 421 p. (in Russian).

13. Demyshev, S.G., 2012. A Numerical Model of Online Forecasting Black Sea Currents. Izvestiya, Atmospheric and Oceanic Physics, [e-journal] 48(1), pp. 120-132. https://doi.org/10.1134/S0001433812010021

14. Pacanowski, R.C. and Philander, S.G.H., 1981. Parametrization of Vertical Mixing in Numerical Models of Tropical Oceans. Journal of Physical Oceanography, [e-journal] 11, pp. 1443-1451. https://doi.org/10.1175/1520-0485(1981)011<1443:POVMIN>2.0.CO;2

15. Lishaev, P.N., 2014. Reanalysis of the Hydrophysical Fields of the Black Sea with Assimilation of Average Monthly Salinity and Temperature Profiles in 1980-1993. In: MHI, 2014. Sovremennoe Sostoyanie i Perspektivy Narashchivaniya Morskogo Resursnogo Potentsiala Yuga Rossii: Tezisy Dokladov Mezhdunarodnoj Nauchnoj Konferentsii, pgt Katsiveli, 15-18 Septembera 2014. [Current State and Prospects for Building up the Marine Resource Potential of Southern Russia: Proceedings of International Scientific Conference. Russia, Katsiveli, 15-18 September 2014]. Sevastopol: ECOSI-Gidrofizika, pp. 186-188 (in Russian).

16. Berrisford, P., Dee, D., Fielding, K., Fuentes, M., Kållberg, P., Kobayashi, S. and Uppala, S., 2009. The ERA-Interim Archive: Version 1.0. ERA Report Series. No. 1. Berkshire, United Kingdom: ECMWF, 16 p. Available at: https://www.ecmwf.int/sites/default/files/elibrary/2009/8173era-interim-archive.pdf [Accessed: 10 February 2018].

17. Dorofeyev, V.L. and Sukhikh, L.I., 2017. Nekotoryye Tendentsii Dolgovremennoy Izmenchivosti Gidrofizicheskikh Poley Chernogo Morya po Rezul'tatam Reanaliza [Some Trends in the Long-Term Variability of the Black Sea Hydrophysical Fields on the Results of the Reanalysis]. Ekologicheskaya Bezopasnost' Pribrezhnoy I Shel'fovoy Zon Morya [Ecological Safety of Coastal and Shelf Zones of Sea], (1), pp. 15-22 (in Russian). 
18. Dorofeev, V.L. and Sukhikh, L.I., 2017. Study of Long-term Variability of Black Sea Dynamics on the Basis of Circulation Model Assimilation of Remote Measurements. Izvestiya, Atmospheric and Oceanic Physics, [e-journal] 53(2), pp. 224-232. https://doi.org/10.1134/S0001433817020025

19. CNES, 2018. AVISO+ - Satellite Altimetry Data [site]. [on-line] Available at: http://www.aviso.oceanobs.com [Accessed: 5 December 2017].

20. Blatov, A.S., Bulgakov, N.P., Ivanov, V.A., Kosarev, A.N. and Tuzhilkin, V.S., 1984. Izmenchivost' Gidrofizicheskikh Poley Chernogo Morya [Variability of the Hydrophysical Fields of the Black Sea]. Leningrad: Gidrometeoizdat, 239 p. (in Russian).

21. Kordzadze, A.A. and Demetrashvili, D.I., 2011. Regional'naya Operativnaya Sistema Prognoza Sostoyaniya Vostochnoy Chasti Chernogo Morya [Regional Operational Forecasting for the Easternmost Part of the Black Sea]. In: MHI, 2011. Ekologicheskaya Bezopasnost' Pribrezhnykh i Shel'fovykh Zon i Kompleksnoe Ispol'zovanie Resursov Shel'fa [Ecological Safety of Coastal and Shelf Zones and Comprehensive Use of Shelf Resources]. Sevastopol: ECOSI-Gidrofizika. Iss. 25(2), pp. 136-146 (in Russian).

22. Korotaev, G.K., Saenko, O.A. and Koblinsky, C.J., 2001. Satellite Altimetry Observations of the Black Sea Level. Journal of Geophysical Research, [e-journal] 106(C1), pp. 917-933. https://doi.org/10.1029/2000JC900120

23. Demyshev, S. and Dymova, O., 2011. Modelirovaniye Tsirkulyatsii Chernogo Morya s Vysokim Prostranstvennym Razresheniyem [High Resolution Modeling of the Black Sea Circulation]. In: MHI, 2011. Ekologicheskaya Bezopasnost' Pribrezhnykh i Shel'fovykh Zon i Kompleksnoe Ispol'zovanie Resursov Shel'fa [Ecological Safety of Coastal and Shelf Zones and Comprehensive Use of Shelf Resources]. Sevastopol: ECOSI-Gidrofizika. Iss. 25(2), pp. 114-135 (in Russian).

About the authors:

Pavel N. Lishaev - Junior Research Associate, Department of Oceanic Processes Dymanics, FSBSI MHI (2 Kapitanskaya Str., Sevastopol, 299011, Russian Federation), Scopus AuthorID: 57193071072, pavellish@mail.ru

Vasiliy V. Knysh - Leading Research Associate, Department of Oceanic Processes Dymanics, FSBSI MHI (2 Kapitanskaya Str., Sevastopol, 299011, Russian Federation), Dr.Sci. (Phys.-Math.), professor, ResearcherID: B-3603-2018, vaknysh@yandex.ru

Gennadiy K. Korotaev - Scientific Supervisor of FSBSI MHI (2 Kapitanskaya Str., Sevastopol, 299011, Russian Federation), Dr.Sci. (Phys.-Math.), professor, ResearcherID: K-34082017,gkorotaev@gmail.com

Contribution of the co-authors:

Pavel N. Lishaev - carrying out the numerical calculation, validation of the results, preparation of graphic materials (diagrams, tables, figures, maps).

Vasiliy V. Knysh - application of the adaptive statistics method for assimilation of temperature and salinity pseudo-measurements of the Black Sea when solving the problem of the Black Sea hydrophysical fields reanalysis for 1993 - 2014, analysis of calculation results, preparation of the initial text of the article.

Gennadiy K. Korotaev - analysis and consolidation of research data, correction of the article; consulting support.

All the authors have read and approved the final manuscript.

The authors declare that they have no conflict of interest. 